\title{
Pengendalian Hipertensi Menggunakan Tanaman Obat Keluarga di Kelurahan Lebak Bandung
}

\author{
Fithriyani $^{1}$, Vevi Suryenti Putri ${ }^{2}$ \\ ${ }^{1,2}$ Program Studi S1 keperawatan,Sekolah Tinggi Ilmu Kesehatan Baiturahim Jambi \\ ${ }^{2}$ Email: fithri.yani25@yahoo.co.id
}

Submitted : 16/03/2021

Accepted: 16/11/2021

Published: 19/11/2021

\begin{abstract}
Hypertension or high blood pressure is characterized by increased blood pressure. The incidence of hypertension continues to increase, the dangers of complications that arise, and the risks of long-term pharmacological treatment. The prevalence of hypertension tends to increase recently. Hypertension that is not treated properly has a high risk of complications including stroke, pulmonary edema, heart attack, and kidney failure. One of the efforts to prevent complications of hypertension is by controlling blood pressure regularly and controlling hypertension, one of which is by using family medicinal plants (TOGA) which are widely grown around residents' homes. The method of activities carried out is in the form of socialization by providing counseling on how to control hypertension by utilizing TOGA. Implementation of activities carried out on residents in the Lebak Bandung Village, Jambi City. The purpose of this activity is to provide an understanding to residents about how to control hypertension through TOGA and can apply it in their respective yards.
\end{abstract}

Key words: hypertension, TOGA

\begin{abstract}
Abstrak
Penyakit hipertensi atau darah tinggi ditandai dengan meningkatnya tekanan darah. Insidensi hipertensi yang terus meningkat, bahaya komplikasi yang ditimbulkan, dan resiko pengobatan farmakologis secara jangka panjang. Prevalensi penyakit hipertensi cenderung meingkat akhirakhir ini. Hipertensi yang tidak ditangani dengan baik beresiko tinggi untuk terjadi komplikasi antara lain stroke, edema paru, serangan jantung, dan gagal ginjal. Salah satu upaya pencegahan komplikasi hipertensi yaitu dengan melakukan kontrol tekanan darah secara berkala dan melakukan pengendalian hipertensi salah satunya dengan menggunakan tanaman obat keluarga (TOGA) yang banyak tumbuh di sekitar rumah warga. Metode kegiatan yang dilaksanakan dalam bentuk sosialisasi dengan melakukan penyuluhan tentang cara pengendalian hipertensi dengan memanfaatkan TOGA. Pelaksanaan kegiatan dilakukan pada warga di Kelurahan Lebak Bandung Kota Jambi. Tujuan kegiatan ini adalah untuk memberikan pemahaman kepada warga tentang cara pengendalian hipertensi melalui TOGA dan dapat menerapkannya di pekarangan rumah masing-masing.
\end{abstract}

Kata kunci : hipertensi, TOGA

\section{PENDAHULUAN}

Penyakit hipertensi atau darah tinggi ditandai dengan meningkatnya tekanan darah yang seringkali merupakan satu-satunya gejala pada hipertensi esensial. Gejala-gejala hipertensi misalnya seperti sakit kepala, mimisan, dan juga pusing, atau juga migren. Beberapa penyebab hipertensi adalah sebagai berikut: faktor usia, ras, latar belakang keluarga, obesitas, kurang aktifitas fisik, merokok, konsumsi garam yang berlebihan, kekurangan potassium, kekurangan vitamin D, minum alcohol, kondisi kronik tertentu (diabetes, kolesterol tinggi, penyakit ginjal), dan kehamilan.

Hipertensi diketahui merupakan faktor resiko dari penyakit yang sangat berbahaya yaitu stroke. Insidensi hipertensi yang terus meningkat, bahaya komplikasi yang ditimbulkan, dan resiko pengobatan farmakologis secara jangka panjang. Prevalensi penyakit hipertensi cenderung 
meingkat akhir-akhir ini. Dari hasil Riskesdas 2018 menunjukkan prevalensi penyakit tidak menular mengalami peningkatan termasuk hipertensi yaitu sebanyak $34,1 \%$. Kenaikan ini berhubungan dengan pola hidup antara lain merokok, konsumsi alcohol,aktivitas fisik,serta konsumsi buah dan sayur.

Hipertensi yang tidak ditangani dengan baik beresiko tinggi untuk terjadi komplikasi antara lain stroke, edema paru, serangan jantung, dan gagal ginjal (Soeryoko, 2010). Selain itu, komplikasi hipertensi dapat menyebabkan kematian jika tidak di tangani dengan segera (Price \& Wilson, 2012). Salah satu upaya pencegahan komplikasi hipertensi yaitu dengan melakukan kontrol tekanan darah secara berkala (American Heart Association/AHA (2014) dan melakukan pengendalian hipertensi dengan salah satunya tanaman herbal yang dapat ditemukan dalam kehidupan sehari-hari dan dipekarangan rumah yaitu menggunakan tanaman obat keluarga (TOGA) .

TOGA dapat berhasiat menjadi tanaman obat karena mengandung senyawa aktif yang memberikan efek sebagai obat seperti flavonoid, tanin, alkaloid, terpenoid dan metabolit sekunder lainnya (Supriatna dkk, 2012). TOGA yang dapat ditanam dan dirawat di pekarangan rumah untuk dimanfaatkan dalam menjaga kesehatan sangatlah beragam, beberapa yang cukup dikenal dari jenis rimpang dan dapat dimanfaatkan untuk kesehatan sehari-hari antara lain adalah jahe merah (Zingiber officinale L), kunyit (Curcuma domestica), dan temulawak (Curcuma xanthorriza Roxb) (Suparni, 2012; Anonim, 2014). Tanaman ini tidak memerlukan tempat yang luas, dan dapat ditanam di pot-pot di perkarangan rumah dengan perawatannya pun cukup mudah. TOGA jenis rimpang ini cukup bermanfaat dalam memelihara kesehatan, seperti menjaga kesehatan pencernaan, menjaga vitalitas daya tahan tubuh, merawat kesehatan organ lambung dan hati, mengurangi keluhan rematik dan nyeri otot, dapat membantu menambah nafsumakan untuk anak-anak, sebagai antibiotika alami, dan manfaat lainnya (Anonim, 2004; Winarto, 2007; Mun'im, 2011). Diharapkan kesehatan masyarakat dapat lebih terjaga dan lebih melakukan upaya preventif untuk mencegah penyakit daripada mengobati penyakit.

Indonesia merupakan daerah yang beriklim subtropis sehingga tanaman yang dapat tumbuh sangat melimpah, bahkan menjadi negara kedua dengan kekayaan keanekaragaman hayati setelah Brazil (Anonim, 2006). Hal ini memungkinkan masyarakat Indonesia dapat menanam bermacam-macam tanaman baik di pekarangan rumah maupun di sekitar rumah. Disetiap rumah biasanya terdapat tanaman yang berfungsi sebagai tanaman hias, penghijauan atau fungsi lainnya. Lahan pekarangan rumah dapat pula ditanam tanaman obat keluarga (TOGA), yang dapat dimanfaatkan untuk menjaga kesehatan masyarakat sehari hari (Winarto, 2007; Suparni, 2012). Diharapkan masyarakat secara luas dapat memanfaatkan TOGA dari lahan pekarangan rumah sehingga membantu meningkatkan kesehatan masyarakat. Namun sayangnya saat ini penanaman dan pemanfaatan tanaman obat keluarga (TOGA) belum dilakukan secara maksimal. Warga Kelurahan Lebak Bandung banyak yang menderita hipertensi. penyebabnya banyak disebabkan oleh banyak factor dan lebih mengarah kepada pola hidup yang kurang tepat.

\section{TARGET DAN LUARAN}

1) Target

Target kegiatan ini warga di Kelurahan Lebak bandung dengan melakukan Sosialisasi pengendalian hipertensi dengan menggunakan pemanfaatan TOGA 
2) Luaran

Luaran kegiatan ini Implementasi pemanfaatan pekarangan rumah dengan menanam TOGA

\section{METODE PELAKSANAAN}

1. Waktu dan tempat

Kegiatan dilaksanakan pada bulan Oktober 2020 s/d Januari 2921 di rumahrumah warga kelurahan Murni Kota Jambi.

2. Sasaran

Sasaran kegiatan adalah warga Kelurahan Murni yang anggota keluarganya memiliki riwayat hipertensi.

3. Bentuk kegiatan berupa:

a. Sosialisasi tentang pengendalian penyakit hipertensi dengan menggunakan TOGA yang tumbuh di sekitar rumah warga.

b. Diskusi dan tanya jawab mengenai berbagai jenis TOGA yang bisa dimanfaatkan untuk pengendalian penyakit hipertensi

\section{HASIL DAN PEMBAHASAN}

Kegiatan pengabdian masyarakat dengan tema "Sosialisasi pengendalian hipertensi dengan menggunakan pemanfaatan TOGA" di Kelurahan Lebak bandung Kota Jambi telah terlaksana pada tanggal 7-10 Oktober 2020. Peserta kegiatan pengabdian masyarakat ini berjumlah 32 orang, dan tim kegiatan yang terdiri dari 2 orang dan mahasiswa. Tempat pelaksanaan dilaksanakan dengan mendatangi rumah-rumah warga sekitar lebak bandung dengan memberikan penjelasan tentang pengendalian hipertensi dengan menggunakan TOGA dan diberikan Leaflet. Adapun tujuan dari kegiatan ini adalah untuk mensosialisasikan pengendalian penyakit hipertensi dan asam urat ringan kepada masyarakat luas agar perkembangan penyakit ini bisa ditekan. Kegiatan ini perlu untuk dilaksanakan mengingat bahwa jumlah penderita hipertensi semakin meningkat.

Kegiatan dimulai dengan meminta izin ke warga untuk melakukan penyuluhan, kemudian melakukan absensi yang dibantu oleh mahasiswa dan setelah itu peserta diberikan materi 10 menit. Secara keseluruhan, kegiatan berjalan dengan lancar serta antusiasme dari peserta juga sangat baik. Pada saat penyampaian materi, peserta sudah cukup paham terkait dengan materi yang dijelaskan. Dengan dilakukannya sosialisasi ini, maka diharapkan pengetahuan masyarakat kelurahan lebak bandung tersebut tentang penyakit hipertensi menjadi lebih baik, sehingga faktor resiko penyakit tersebut akan berkurang dan kualitas hidup penderita menjadi meningkat.

Dalam sesi tanya jawab setelah penyampaian materi, banyak dari warga yang ternyata belum tahu pasti bagaimana mencegah dan mengendalikan hipertensi, termasuk gaya hidup yang harus dilakukan, makanan yang diperbolehkan dan yang tidak diperbolehkan serta manfaat dari tanaman obat yang bisa digunakan untuk meringankan penyakit hipertensi. Pertanyaan seputar gejala umum hipertensi dan pola makan yang tepat, dan aktivitas yang dianjurkan pada penderita atau aktivitas-aktivitas yang dapat mencegah terjadinya hipertensi dan diabetes banyak dilontarkan oleh peserta sosialisai tentang penyakit. Hal ini menunjukan bahwa masyarakat sangat peduli dengan kesehatan dan masyarakat membutuhkan informasiinformasi tentang masalah kesehatan yang kadang-kandang masih kurang pemahamannya. Oleh karena itu, kegiatan semacam ini sangat diperlukan bagi masyarakat dengan materi yang menyesuaikan dengan permasalahan yang dialami oleh masyarakat di daerah tersebut. 


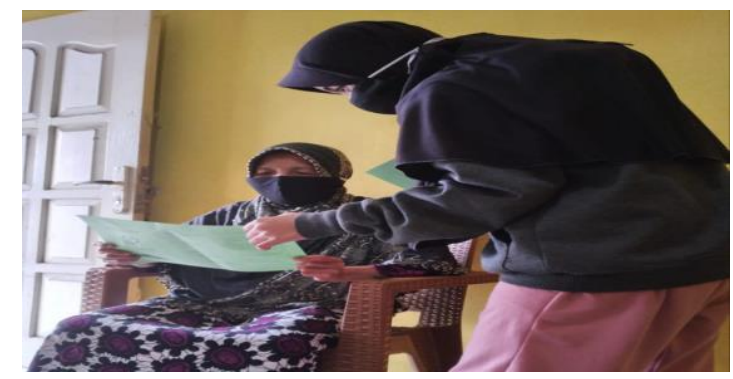

Gambar 1. Sosialisasi TOGA kerumah warga

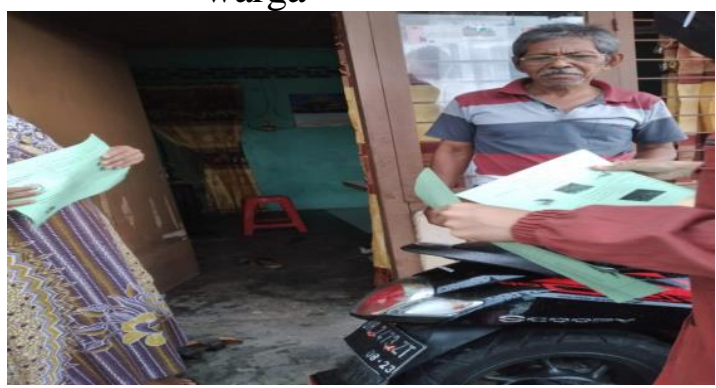

Gambar 2. Diskusi dengan warga tentang materi sosialisasi

\section{KESIMPULAN DAN SARAN}

\section{Kesimpulan}

Peserta mampu memahami cara pengendalian hipertensi dengan menggunakan TOGA yang bisa didapat pada lingkungan disekitar

2. Saran

Perlu dilakukan sosialisasi tentang pengolahan TOGA agar lebih praktis dalam penggunaannya dan dimanfaatkan oleh warga pada umumnya.

\section{UCAPAN TERIMAKASIH}

Ucapan terimakasih kepada kelurahan Lebak Bandung yang telah menfasilitasi kegiatan ini sampai selesai dan kepada Stikes baiturahim Jambi yang telah mendanai kegiatan pengabdian ini dalam menunjang tri darma perguruan Tinggi.

\section{DAFTAR PUSTAKA}

Alexander et al, 2014 Patient Knowledge and Awareness of Hypertension Is Suboptimal: Results From a Large Health Maintenance Organization.

Anonim.(2014),Pedoman Rasionalisasi Komposisi Obat Tradisional,
Departemen Kesehatan RI, Badan POM, Direktorat Obat Asli Indonesia, Volume 1. ISBN 978-602-7899-25-4

Harfiani E,dkk. Pemberdayaan masyarakat RW 03 Depok Jaya dalam memanfaatkan Toga di lahan pekarangan rumah sebagai minuman kesehatan. Prosiding seminar hasil pengabdian kepada masyarakat. Departemen farmakologi FK UPN veteran Jakarta.

Hastuti, Sriadi Setyawati,dan Nurul Khotimah. (2014), Pemberdayaan Ibu Rumah Tangga Di Desa Purwobinangun Kecamatan Pakem Kabupaten Sleman Dalam Penanaman Dan Pemanfaatan Tanaman Obat Keluarga (Toga),Universitas Negeri Yogyakarta.

Kementerian Kesehatan RI,(2011),100 Top Tanaman Obat Indonesia, Badan Penelitian dan Pengembangan Kesehatan Balai Besar Penelitian dan Pengembangan Tanaman Obat dan Obat Tradisional.

Kementerian Kesehatan RI, (2011),Pedoman Pengolaan dan Pemanfaatan Tanaman Obat Keluarga (TOGA), Direktorat Bina Pelayanan Kesehatan Tradisional Alternatif dan Komplementer DIRJEN Bina Gizi dan Kesehatan Ibu dan Anak, Jakarta.

Kementerian Kesehatan RI. (2012),Pedoman Penilaian Pengelolaan dan Pemanfaatan TanamanObat Keluarga (TOGA),Jakarta

Riset Kesehatan Dasar (RisKesDas). (2018). Laporan hasil riset kesehatan dasar 2013. Jakarta

Soeryoko, H. (2010). 20 tanaman obat terpopuler penurun hipertensi. Yogyakarta: Andi Off set

The Journal of Clinical Hypertension. 5. 254-260. American Heart Asosiasion (AHA). (2014). An Effective Approach to High Blood Pressure Control 